\title{
BMJ Global Health Involving im/migrant community members for knowledge co-creation: the greater the desired involvement, the greater the need for capacity building
}

Tanvir Chowdhury Turin, ${ }^{1,2,3,4}$ Nashit Chowdhury, ${ }^{1,2}$ Sarika Haque, ${ }^{1}$ Nahid Rumana, ${ }^{5}$ Nafiza Rahman, ${ }^{6}$ Mohammad A A Lasker ${ }^{6}$

To cite: Turin TC, Chowdhury N, Haque $\mathrm{S}$, et al. Involving im/ migrant community members for knowledge co-creation: the greater the desired involvement the greater the need for capacity building. BMJ Global Health 2021;6:e007602. doi:10.1136/ bmjgh-2021-007602

Handling editor Seye Abimbola

Received 2 0ctober 2021 Accepted 3 December 2021

Check for updates

(c) Author(s) (or their employer(s)) 2021. Re-use permitted under CC BY-NC. No commercial re-use. See rights and permissions. Published by BMJ.

For numbered affiliations see end of article.

Correspondence to Dr Tanvir Chowdhury Turin, Room G012, Health Sciences Center, 3330 Hospital Dr. NW, Cumming School of Medicine, University of Calgary, Calgary T2N 4N1, Alberta, Canada; turin.chowdhury@ucalgary.ca

\section{ABSTRACT}

Researchers need to observe complex problems from various angles and contexts to create workable, effective and sustainable solutions. For complex societal problems, including health and socioeconomic disparities, crosssectoral collaborative research is crucial. It allows for meaningful interaction between various actors around a particular real-world problem through a process of mutual learning. This collaboration builds a sustainable, trustbased partnership among the stakeholders and allows for a thorough understanding of the problem through a solutionoriented lens. While the created knowledge benefits the community, the community is generally less involved in the research process. Often, community members are engaged to collect data or for consultancy and knowledge dissemination; however, they are not involved in the actual research process, for example, developing a research question and using research tools such as conducting focus groups, analysis and interpretation. To be involved on these levels, there is a need for building community capacity for research. However, due to a lack of funds, resources and interest in building capacity on the part of both researchers and the community, deeper and meaningful involvement of community members in research becomes less viable. In this article, we reflect on how we have designed our programme of researchfrom involving community members at different levels of the research process to building capacity with them. We describe the activities community members participated in based on their needs and capacity. Capacity-building strategies for each level of involvement with the community members are also outlined.

\section{BACKGROUND}

Conventional knowledge creation or research approaches for developing solutions to community issues is becoming increasingly challenging due to the complexity and multidimensionality of the many societal issues we currently face. ${ }^{1}$ It is critical for researchers to view complex problems from numerous angles and perspectives to create meaningful, effective and sustainable solutions. This is

\section{Summary}

- Interdisciplinary and cross-sectoral collaborative research allows meaningful interaction for a solutionoriented approach to a complex societal problem through a process of mutual learning.

- Community-based research needs to involve participants beyond tokenism, but with a meaningful and pragmatic purpose and approach.

- The programme of research needs to identify community participants at a variety of levels and develop a strategy to involve them in different roles according to their interests and abilities.

- The programme of research needs to have adequate facilities to train interested community members to involve them more deeply in the research process and to maximise their input in the research being undertaken in their community.

- Capacity-building activities need to be sustainable to ensure the efforts do not degenerate after a single project.

- Capacity-building activities need to be designed so that they empower the participants and the individual community members and that the community benefits from the activities are understood. The gain to researchers also should be informed clearly to sustain partnerships based on trust and mutual benefit.

especially true for issues faced by racialised/ immigrant communities in their adopted homes, where their health and wellness issues are influenced by cultural differences, social and environmental determinants and systemrelated factors. ${ }^{23}$ Adopting an interdisciplinary and cross-sectoral collaborative research approach allows meaningful interaction across various actors around a particular realworld problem through a process of mutual learning. ${ }^{4}$ This approach allows a deeper multi-level understanding of the problem through a solution-oriented lens and could 
Conventional approach: actors across roles
Integrated approach: actors across roles
- Society

- Community Members

Beneficiaries Members

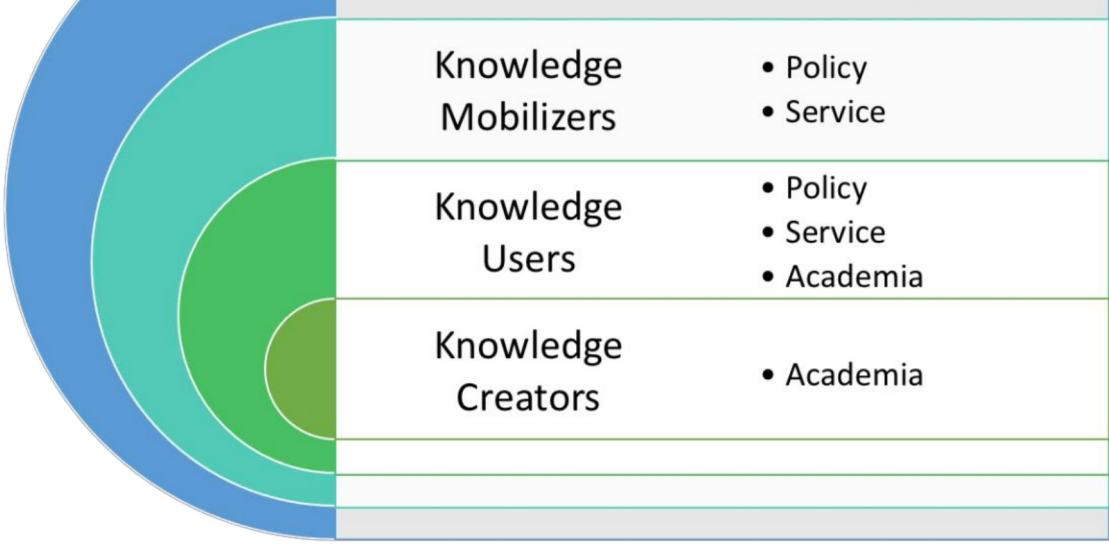

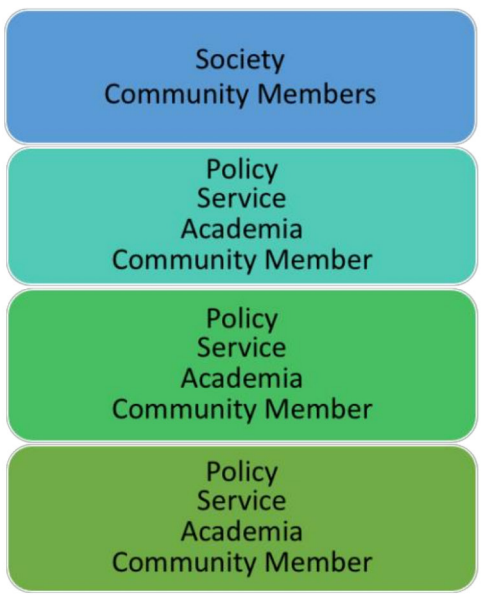

Community Member

\section{Knowledge Roles}

\section{Knowledge Actors}

Figure 1 Different types and levels of knowledge actors or stakeholders through cross-sectoral collaboration in the research or knowledge creation process: conventional versus integrated approach.

provide a promising response to addressing complex societal and sustainability challenges. ${ }^{56}$

The importance of involving different levels of actors or stakeholders through cross-sectoral collaboration in the research or knowledge creation process has been gaining momentum lately. Among the different types and levels of knowledge actors (figure 1), communities have traditionally been thought of as only knowledge beneficiaries. Researchers or academics can be seen as knowledge creators and policy-makers or service providers as knowledge users, all of whom could assume the role of knowledge mobilisers depending on the activities required to apply the knowledge and related products obtained from their research to create social or economic impacts that benefit communities and society. Despite all knowledge being created for the benefit of the community, communities generally have been seen as the place to do research or as the data source-rather than considering and treating them as a partner in the programme of research. Community-based research needs to take the approach of for the community, in the community, and with the community. ${ }^{7}$ Researchers, particularly population health researchers, generally ensure the focus is on for the community and in the community, but meaningful research with the community is lacking. ${ }^{8}$

Community-based participatory research, ${ }^{9}$ integrated knowledge translation ${ }^{10}$ or human-centred design strategies $^{11}$ are people-centred approaches of conducting research that promote the concept of involving community members across the research process continuum. ${ }^{1012}$ These approaches emphasise a different level of actor involvement, especially for the members of the community in which the research is being conducted. Forming partnerships between academics and non-academics fosters an environment in which there is mutual understanding and shared ownership and decision making. In contrast to the conventional research approach, it treats community members as coresearchers and values their perspectives and knowledge as valid sources of information. Community members are included across the various steps of the research process, from forming an initial research question to evaluating the programme of research with an aim of co-creating knowledge. ${ }^{13}$

Involving community members as participants and knowledge disseminators-in other words, undertaking research 'for the' and 'in the' community-is more prevalent. This requires less capacity from the community. On the other hand, research 'with the' community as empowered and equitable partner requires building community capacity to the level that they understand basic research concepts around methods, ethics and interpreting research data. Community participants generally do not have that capacity and researchers may not have the necessary funds, resources or interest to build the capacity necessary to undertake research "with the' community. ${ }^{14}$ In this article, we reflect on how we have designed our programme of research by involving community members at different levels and strived to build capacity among them.

\section{COMMUNITY MEMBER INVOLVEMENT}

The programme of research: equitable health for racialised and im/migrant communities

As part of our community-engaged programme of research on racialised and $\mathrm{im} /$ migrant health and wellness 


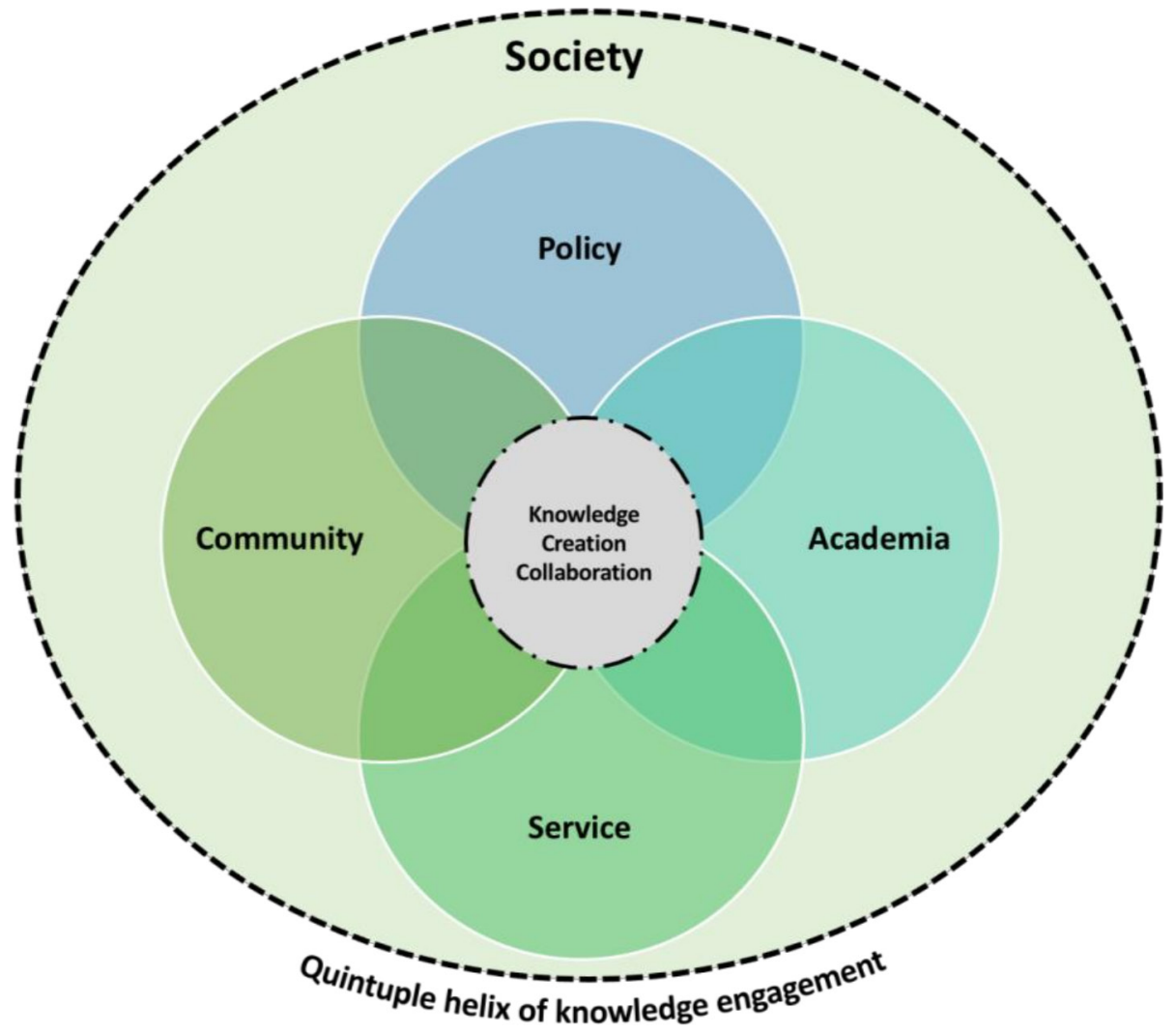

Figure 2 Quintuple helix brought together in our guiding conceptual model of collaboration for knowledge creation (the collaboration, across academia, service, policy and community, in the society).

issues, we have been conducting studies on primary care access barriers and possible solutions with an immigrant/ racialised community in Canada. We aimed at meaningful and active involvement of community members alongside policy-makers and service providers in identifying research questions, priority setting, conducting research, cocreating knowledge products and knowledge translation or mobilisation activities. In our collaboration for knowledge creation, our guiding conceptual model encompassed helix of actors (academia, service, policy and community) brought together in a knowledge society ${ }^{15}$ (figure 2). This model aspires to generate, share and make knowledge available to all members of society. Our community member involvement strategies and efforts were embedded within a participatory approach, thus it entailed ongoing relationships between the researchers and community representatives. Using a South-Asian community (Bangladeshi-Canadians: people immigrating from Bangladesh to Canada and currently residing in Calgary, Alberta) as a case, the learnings from the studies ${ }^{16-19}$ conducted under our programme of research informed our understanding of how to involve immigrant community members in community-based research through various stages of engagement towards active collaboration. These activities not only allowed us to collaborate with community members but to value their knowledge and expertise and view them as partners and coresearchers. Members of our research team were fluent in Bangla and English, allowing us to bridge any communication and language gaps.

\section{Community member involvement in our program of research}

Our programme of research actively sought the involvement of any community members who were interested in becoming more involved in the research and associated activities. During our initial efforts at meaningful community engagement, we shared the open invitation to join our programme of research with community members at a variety of levels. We envisioned that involving community members actively in the programme of research in different roles would create a feeling of ownership within them that would lead to a better uptake of the knowledge in the community.

Outreach activities to invite and involve community members Our initial outreach activities involved being present at different community events, using social media to promote involvement and reaching out to community champions/influencers. Table 1 summarises our different outreach initiatives.

\section{Different levels of involvement of community members}

Our engagement activities led to a number of community members being involved at different levels and in different roles (figure 3). The majority of community members who engaged with us did so to be informed. During our different events and activities, community members 
Table 1 Outreach strategies for community member involvement

Booths/stalls at community cultural events
Immigrant communities have cultural festivals where different types of food or clothing stalls are usually present. To reach out to general community members regarding our programme of research, we started being present at those events and had our booths set up. Our booths were decorated with pull-up banners and posters. We also distributed leaflets and handouts to the people visiting those events. For those who showed interest, we shared our programme of research with them. Through this process, we engaged with a number of community members who got involved with us at different levels.

Social media promotion

We were also showcasing different activities associated with the programme of research, as well as health and wellness information, through different social media channels. Engagement efforts through this channel were geared more towards disseminating information regarding who we were, so community members would be familiar with us when we reached out to them for their involvement in our activities.

Community-level health and literacy workshops on different issues

We started organising workshops on different health and wellness literacy issues for community members. The topics ranged from parenting issues and chronic disease management to mental health. A number of community members actively became involved in our programme of research through this avenue.

Community member mentoring and training opportunities

During the later stages of our activities, we initiated efforts to mentor community members who were interested in developing skills around research, education and promotion activities related to our programme of research. A number of community members identified that through this process they could contribute to our research and could benefit from the programme of research. This approach provided us with a stronger level of involvement.

Community-engaged learning for students belonging to the community
We also created summer research opportunities in our programme of research to provide opportunities to students belonging to the community (not necessarily our university students) to be involved in research within the community to which they belong. expressed interest and agreed that we should keep in touch with them about our activities and advancements. Within this group, a number of community members participated in our studies as we conducted research. We also had a number of community members express interest in becoming involved at a deeper level. Based on their interest and the amount of time they could manage; they were involved in a consultative role or became more involved in executing research activities such as helping with recruitment or actively disseminating survey questionnaires. As our research progressed, a number of community members indicated a desire to collaborate as partners. They acted in a coinvestigator role from the community side in our research projects. A few of them also became involved in leading some components of our research projects, such as knowledge translation or community engagement.
Different levels of Community Member Involvement

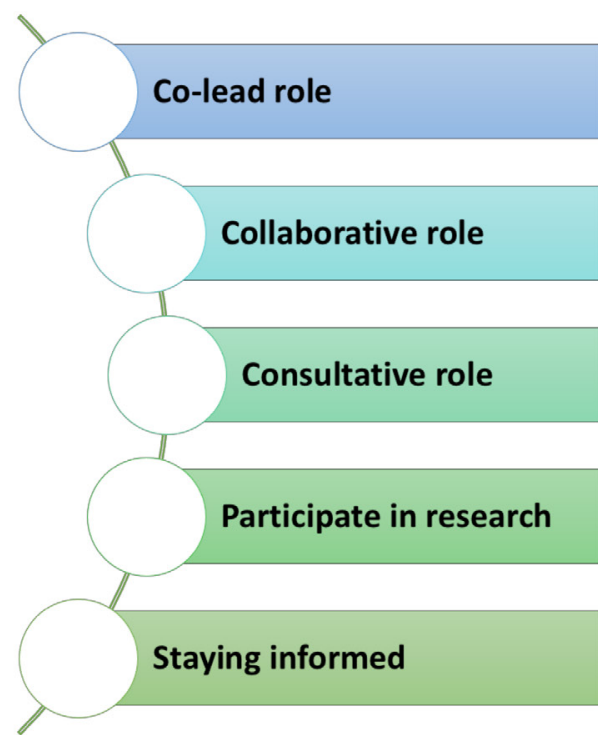

\&

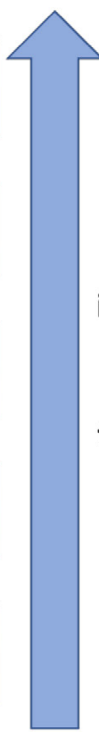

the

involvement

$-$

the greater

the need for

capacity

building
Required Capacity

Skilled in the methods related
to the component leading

Comprehend the different

steps in research process

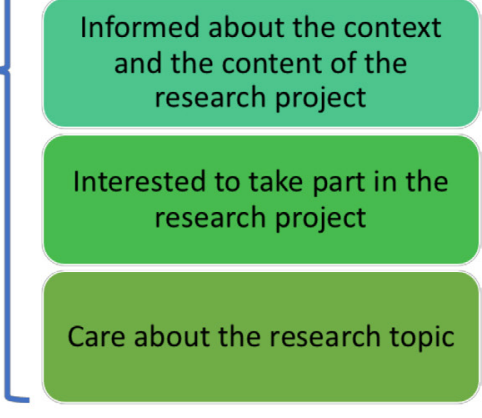

Informed about the context $d$ the content of the research project

Figure 3 Involvement of community members at different levels and in different roles resulting from our engagement activities and the capacity required to fulfil those roles. 
Involvement Matrix

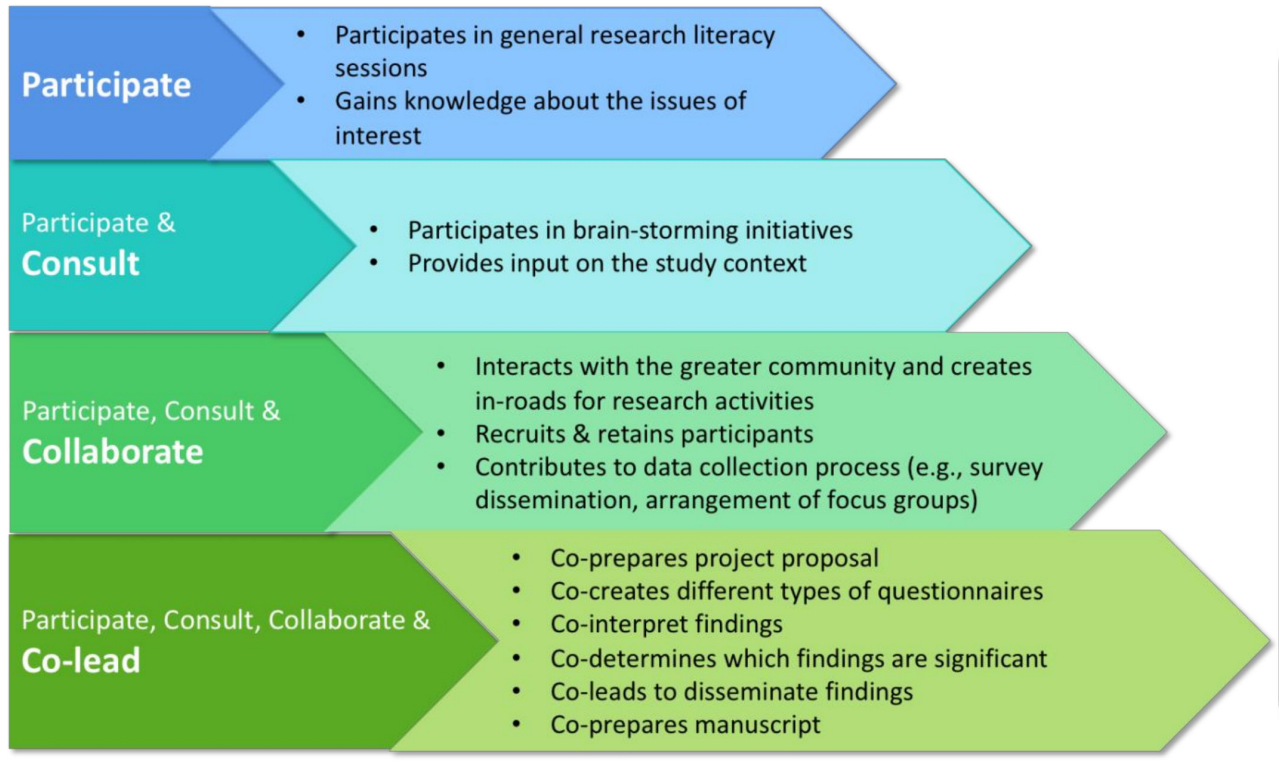

Benefits

- Increased knowledge and awareness of the topic of interest

- Increased practical and research skills

- Mutual understanding

- Shared decision making

- Progress in personal and career goals

- Opportunities to communicate, think critically, problemsolve, and collaborate

- Expansion of social support networks

- Empowerment of communities

Figure 4 Activities of and benefits for community member across involvement matrix in research.

\section{Activities of community members in research projects}

The community member participants contributed to our research projects through a range of activities (figure 4). Their inputs were imperative to our approach of cocreating the research themes. Undoubtedly, our success in participant recruitment was substantially driven by the community participants. We had community members who took on the transcription and translation component associated with our studies. We collaboratively took on making sense of the data we collected with those members who collaborated with us closely. Our research team analysed the data, and we discussed the results with the community member collaborators as our work progressed. When we drafted the manuscripts, the community member collaborators were also part of the writing group and contributed contextualisation of the storyline to the manuscripts. The community member collaborators were also instrumental in taking the results back to the grassroots community through their outreach.

\section{CAPACITY-BUILDING NEEDS OF COMMUNITY MEMBERS AND OUR APPROACH \\ The necessity of capacity building}

Capacity building is crucial for all members of a research team, including both academics and community members. Activities that promote capacity building allow researchers to better understand the research process and the theory behind it. This understanding allows everyone to contribute effectively to the programme of research and may occur through forming and defining a research question, setting appropriate goals, collecting data, interpreting results and presenting data in a manner that can be understood by a lay audience. In our community member involvement, research capacity building was needed as their involvement level increased. This need was evident especially when the community members' involvement grew to the level of partnered collaboration and leadership roles. There was a need for overall exposure to the basics of the context of our programme of research and related topics, as well as a general sense of different research methodologies.

\section{Initiatives towards fulfilling the needs}

To fulfil these needs, over time we rolled out a number of initiatives towards engagement and capacity building of the involved community members. Depending on their desired level of involvement, members were free to join any of the initiatives they desired. The initiatives below address the different levels of skill-set building needed across the different levels of community member involvement.

\section{General research literacy sessions}

We have been conducting monthly general research literacy-focused lunch and learn sessions. The target audience of these sessions is not only community members but also any member of policy-making or service-providing organisations. These sessions mainly focus on a very generalised overview of different types of knowledge creation and mobilisation approaches. A number of participants from service-providing organisations who attended these sessions also could be identified as community members. This initiative was aimed at those looking for initial involvement at a broader level.

\section{Community think tank initiative}

Participating in a community think tank was a second level step for community members to explore if they gained deeper interest following the general research and literacy sessions. This initiative is offered on a specific weekday evening on a monthly basis. In these 
sessions, contextual information on different community health and wellness issues, especially social determinants of health issues, are presented to participants. We initiate discussion about the issues, how communities are affected by them, and how these issues can be addressed collectively. If participants indicate any specific topics of interest, we ask whether they would like us to prepare and bring information about them for discussion in future sessions.

\section{Community scholar and citizen researcher programme}

Our focus on community member capacity building attracted a number of community members to the Community Scholar and Citizen Researcher initiative and helped us work more meaningfully with the community. This programme is more focused on capacity building so that community members can collaborate with us by being part of more hands-on research activities. For our purpose, we considered community scholars as those community members who were interested in the research topic and provided support to us in carrying out the study without being formally involved (ie, an employed member of the research team). Citizen researchers are those community members who became directly and more actively involved in the research process (ie, a recognised volunteer or a casually employed member of the research team). A number of community members involved in this initiative have moved forward in their existing careers or have had the opportunity to develop and progress with new careers. For example, capitalising on the experience and knowledge gained with us, some members obtained employment as full-time/part-time research assistants/ coordinators with other research teams and in other activities. While some programme members have moved ahead, and new members took their place in the process, one highlight is that former members have now become enthusiastic champions of our programme of research. Though we have a monthly meeting for this programme, participants take on hands-on activities from one meeting to the next under the supervision of researchtrained personnel as part of their learning activity. They were also briefed about research ethics and were encouraged to take the research ethics course (eg, Tri-Council Policy Statement: Ethical Conduct for Research Involving Humans (TCPS 2)) to understand the ethical aspects of research involving human subjects.

\section{Project-specific skill building workshops}

We also have arranged a number of project-specific workshops for community members who wanted to get involved in research project activities. These predominantly were driven by the skill sets needed for the successful completion of specific research projects. We have conducted a number of workshops, including workshops on the systematic review process, conducting focus groups, community engagement, manuscript writing and creating posters or presenting at conferences. This initiative was aimed at community partners who saw themselves as co-researchers and wanted to develop their skills to increasingly contribute to the programme of research. Participants in this level were required to take a research ethics-related course (ie, TCPS 2) and hands-on training.

\section{Benefits for us (researchers) of involving community members}

Apart from the hugely valuable guidance received for developing the programme of research, our research activities hugely benefited from the deeper involvement of the community members. Our research programme gained valuable social capital, which positively impacted our overall community engagement efforts. As previously mentioned, we achieved relative success with participant recruitment and knowledge dissemination activities. For example, we collected more than four hundred responses to a survey, with relative ease, from the BangladeshiCanadian community to identify community-driven priorities for our programme of research. ${ }^{19}$ The community member involvement, in turn, resulted in more community member involvement as our programme of research moved forward. By creating intricate teams and networks of researchers and community members with different backgrounds, skills and knowledge, we were able to gain a richer understanding when interpreting the findings. We involved our research team's community scholar and citizen researcher members to interpret the findings regarding equitable access to healthcare faced by Bangladeshi-Canadians. ${ }^{16-18}$ They have been an integral part of our manuscript writing as co-authors. Having the engagement from large and diverse community-level participants also allowed for the dissemination of results to a larger audience. Overall, a community-engaged approach provided us with a broader perspective of the topic of interest and a better understanding of the needs of the community. This type of insight is helping us to develop studies to explore further issues to reduce gaps in evidence. As a continuation of this understanding, we have organised a Bangladeshi-Canadian community think tank to work further to identify the root causes behind the equitable access issues. We meet on a regular basis to discuss the research topic and process as we move forward. Building such trusting partnerships can allow us to collaborate in those future projects and create an overall sustainable programme of research.

\section{Potential benefits for community members}

For a participatory research programme to be effective, there must be clear and visible positives for participants. There were a number of benefits we feel community members experienced. This programme of research allowed community members to gain knowledge and awareness about the topic of interest. Considering them as coresearchers and experts who can analyse situations and inform research can empower them and the communities. They may have gained practical and research skills that not only helped us build capital but helped community participants progress in their current and 
future career goals. For instance, some of our community members who actively participated in the research have made progress as a research/programme coordinator in their personal careers in health services and non-profit organisations. Also, our projects gave community members the opportunity to communicate, think critically, problem-solve and collaborate. Collaborating with others through research can allow participants to get to know one another and increase their social support networks. Additionally, taking on a leadership role in our programme of research can motivate participants to embark on a journey of personal fulfilment. We observed that the community members involved in our programme of research felt empowered. As our programme of research is built on addressing the issues of equity, diversity and inclusion-the involved community member became more conscious of these issues and became equity champions in their own ways. They become more active within the communities and social circles and continued taking part in future projects.

\section{IMPLEMENTING COMMUNITY MEMBER INVOLVEMENT Factors those influenced community member involvement}

There are a number of factors that worked positively in our initiative towards community member involvement in our programme of research. Our outreach activities in the initial stage were based on the approaches of listening to community members with a clean slate and conducting events at the community level with no strings attached. Enacting these approaches in a continuous manner provided us with a trust-building opportunity. To accommodate for everyone's busy schedules, we implemented activities during days and times that worked best for interested members. We have set the focus group discussion/ interview location at places they know, trust, and closest to the most participants. When community members started to get involved in our work, clear communication, discussion on mutual expectations, a flexible approach, facilitating capacity building, adopting a strategic approach towards a win-win scenario and ensuring their visibility through credit sharing allowed for fruitful partnership development. It is also important for academics to understand and feed the community member participants' motivation. A feeling that their motivations or original intentions were not being addressed can lead to a sense of not feeling involved or needed. This can translate to a lack of enthusiasm and desire to engage in further research. Community member participants are more likely to continue to work with researchers if they are able to witness their efforts come to a fruitful completion. Gaining new knowledge and being credited for that can be exciting and develop the interest that is necessary to sustain partnerships with community members. To that end, we created opportunities for community member participants to be part of our manuscript writing group or copresent at conferences.
Within the community where we conducted our research, we identified subgroups of members who could not become active members of the programme of research but were interested in participating in activities such as focus groups and interviews. We arranged gift cards, food, transportation, and babysitting support to assist their participation in the activities and events. In many instances, however, we could not arrange compensation for our community scholars or citizen researchers for their time and knowledge. There were some project based opportunities for coordination or research assistant roles, which we opened up to the community members who decided to develop a career in health and social care research.

\section{Sustainability of the community member involvement}

The most important realisation that we had in terms of the sustainability of conducting research in an engaged way is that the current funding or resource mechanisms employed by the funding bodies are not conducive to sustainability. Research funding, in general, is single project-based and study ideas ranked highly become successful for funding, as the process is competitive. Researchers tend to leave the community once a particular research project is done, mainly due to not securing funding for the next phase. This affects community members' active involvement, especially those who require support to be involved in research activities. This is not a healthy approach for either researchers or communities and inhibits knowledge mobilisation. Community members may feel exploited when researchers approach them with ideas of working together only to leave them once data collection is complete. We approached the journey of our programme of research as an infinite process. We always explain the background of our work, the scenario around securing of grants and resources, and the ideal deliverables to potential community members. We have open discussion towards how we can create a win-win scenario for both parties within the constraints we face. We brainstorm our working plan based on the mutual understandings that when there are external resources (eg, grants) we will share those appropriately. Or when we do not have suitable resources, we will continue with activities at a slower pace based on our own in-kind contributions (eg, facilitating student training, knowledge mobilisation activities). These approaches also illustrated to communities that the researcher did not parachute out of the community after data collection, but rather is standing by their side working for and with them, thus building trust among them regarding the researcher and the programme of research. This approach of research as an infinite or never-ending process, one in which baby-step activities are incorporated based on the resource availability or not, helped us to sustain the community member involvement in our programme of research. It should be acknowledged that these approaches do not fully ensure equitable involvement of community members who need resources to 
permit them to actively participate in research activities. While we make every effort to ensure our research studies capture the voices of the community population who require support for their participation, as a programme of research we have not fully overcome the limitation of ensuring their continuous and active involvement with our research programme due to resource constraints. On the other hand, we feel privileged as we were blessed by community members who graciously got involved with us on a voluntary manner through their time and knowledge. Undoubtedly, without these valuable contributions, we could have never moved forward with our community engaged programme of research.

\section{Community member capacity building: a responsibility of the academics}

In community-engaged research, immigrant/racialised community members are often involved only to support-rather than to challenge-the research ideas, questions, framework and concepts. ${ }^{20}$ Involving community members in research with decision-making capacity ensures a bottom-up approach which is crucial for correctly identifying the community needs and improvement of the communities. ${ }^{21}$ There is an optics that the researchers tend to commodify and capitalise research on immigrant/racialised populations rather than channel that towards the actual improvement or empowerment of the communities. Researchers may argue that the community members do not have the capacity to participate in the research with shared decision-making capacity. However, we believe that it is the researchers' social responsibility to make the first step towards building the capacity among the grassroots communities so that they can participate in the research more meaningfully. The researchers need to dedicate their brain, time and resource and develop strategies to ensure that the community members involved in their research develop the capacity to understand the research process and contribute to all phases of the research from developing researcher questions to interpretation of the findings to mobilising the knowledge.

\section{CONCLUSION}

In this article, we have reflected on our experience in involving community members in our programme of research. Meaningfully involving community members in research projects or the programme of research requires strategic planning where academics must aspire to convert the initial engagement to a partnership. Involving community members will occur at different levels. Most of the people will tend to become involved at the stay in touch level. The deeper the involvement, the less people are willing to become involved at that level for practical reasons. There might be instances where the same people will continue to be involved in a programme of research over time. Researchers need to be aware of this phenomenon and avoid being complacent. Rather, efforts to involve community members in a programme of research need to be dynamic and continuous. Involving new community members should be undertaken proactively, as encouraging such involvement helps ensure the community is mobilised towards more impactful knowledge utilisation. For the involvement of community members to be fruitful, it is the responsibility of academics to facilitate the capacity building of community members. This capacity building will contribute towards stronger collaboration and ensure quality research. The deeper the involvement of the community member, the more capacity building that is required. This capacity building initiative will ensure a win-win scenario for both the researchers and the community members.

Researchers who are using the community participatory approach need to be truly committed to the approach. Only focusing on advancing their research projects instead of on community empowerment will lead nowhere. ${ }^{22} 23$ Researchers can involve community members in identifying problems or at least ensure that the chosen research problem aligns with their priorities. ${ }^{17}$ Also, there need to be tangible benefits for the community members, of which researchers need to ensure community partners are aware about. ${ }^{24}$ Mutual respect must be established to create a trusting environment, and clear communication is imperative. Having regular discussions about the journey to ensure everyone is on the same page and being flexible is important for mutually rewarding involvement.

We would like to acknowledge that our research team also had 'insiders' or 'partial insiders' positionally ${ }^{25}{ }^{26}$ in the Bangladeshi-Canadian immigrant community. The research lead (TCT) belongs to that community and is equally proficient in both Bangla and English languages. In building a community-engaged programme of research, we commenced engagement with the Bangladeshi-Canadian community, where we had relatively easier access to different levels of the community. While we were successful in getting community members to participate and articulate opinions, we want to point out the extra work that even we as insiders have been required to undertake to combat the reluctance of community members to participate and persuade them to join. We believe our position of being 'insider enough' (due to shared ethnicity and common immigrant background) and yet having some professional distance eased community members to interact with us acquiescently. Though we represented the University but making ourselves available on community members' own turf helped our programme of research to move forward.

We believe our learnings from involving community members in research can help guide the change from a conventional involvement approach to a meaningful community-involved research approach. We have been undertaking cross-sectoral and transdisciplinary knowledge translation activities where meaningful community engagement is at the core. Our pragmatic experience from the field on how to make it happen will enable us to meaningfully involve the community members and work towards empowering them for advocacy and capacity building. 
The goal is to facilitate the coproduction of knowledge by making community members skilled partners who will be able to contribute to the programme of research and more impactful knowledge creation and knowledge mobilisation.

\section{Author affiliations}

${ }^{1}$ Department of Family Medicine, Cumming School of Medicine, University of Calgary, Calgary, Alberta, Canada

${ }^{2}$ Department of Community Health Sciences, Cumming School of Medicine, University of Calgary, Calgary, ALberta, Canada

${ }^{3}$ The Libin Cardiovascular Institute, Cumming School of Medicine, University of Calgary, Calgary, Alberta, Canada

${ }^{4} 0$ 'Brien Institute for Public Health, Cumming School of Medicine, University of Calgary, Calgary, Alberta, Canada

${ }^{5}$ Sleep Center, Foothills Medical Center, University of Calgary, Calgary, Alberta, Canada

${ }^{6}$ Community Based Citizen Researcher, Calgary, Alberta, Canada

Twitter Tanvir Chowdhury Turin @drturin

Acknowledgements We acknowledge the wholehearted engagement and gracious support we have received from the immigrant community members in Calgary. Also, we appreciate the compassionate encouragement and assistances we have received from all the socio-cultural organizations working in the grassroots community. We would also like to acknowledge the support from our academic peers and institutional leaderships towards this community-engaged program of research and our knwoledge engagement efforts.

Contributors TCT, NR and MAAL conceived the study idea. TCT, NC, NRu, NRa and MAAL conducted the study. TCT, NC and SH drafted the manuscript. NRu, NRa and MAAL critically reviewed the manuscript. NRu and MAAL provided important perspectives as community member researchers. TCT takes the responsibility for the overall content as the guarantor.

Funding The authors have not declared a specific grant for this research from any funding agency in the public, commercial or not-for-profit sectors.

Disclaimer The views expressed here are those of the authors and are based on their working expeirence, positionality, and reflections.

Competing interests None declared.

Patient and public involvement statement While preparing this manuscript, we have partnered actively with citizen researchers at the community level from the very beginning. We had regular interactions with them to get their valuable and insightful inputs in shaping our reflections. Their involvement in this paper also provided a learning opportunity for them and facilitated them to gain insight on kwnoeldge engagement. All authors support the greater community / citizen / public involvement in research in an equitable manner.

\section{Patient consent for publication Not applicable.}

Ethics approval Ethics approval was not required because this is a reflection piece by researchers on the lessons from equity, diversity, inclusion (EDI) and social accountability driven program of research which focuses on cross-sectorial and transdisciplinary scholarship where meaningful community engagement is at the core. It does not include any data analysis on any primary or secondary data.

Provenance and peer review Not commissioned; externally peer reviewed.

Data availability statement There are no data in this work.

Open access This is an open access article distributed in accordance with the Creative Commons Attribution Non Commercial (CC BY-NC 4.0) license, which permits others to distribute, remix, adapt, build upon this work non-commercially, and license their derivative works on different terms, provided the original work is properly cited, appropriate credit is given, any changes made indicated, and the use is non-commercial. See: http://creativecommons.org/licenses/by-nc/4.0/.

\section{REFERENCES}

1 Newig J, Jahn S, Lang DJ, et al. Linking modes of research to their scientific and societal outcomes. Evidence from 81 sustainabilityoriented research projects. Environ Sci Policy 2019;101:147-55.

2 Ahmed S, Shommu NS, Rumana N, et al. Barriers to access of primary healthcare by immigrant populations in Canada: a literature review. J Immigr Minor Health 2016;18:1522-40.
3 Chowdhury N, Naeem I, Ferdous M, et al. Unmet healthcare needs among migrant populations in Canada: exploring the research landscape through a systematic integrative review. J Immigr Minor Health 2021:23:353-72.

4 Jahn T, Bergmann M, Keil F. Transdisciplinarity: between mainstreaming and marginalization. Ecological Economics 2012;79:1-10.

5 Hirsch Hadorn G, Bradley D, Pohl C, et al. Implications of transdisciplinarity for sustainability research. Ecological Economics 2006;60:119-28.

6 Lang DJ, Wiek A, Bergmann M, et al. Transdisciplinary research in sustainability science: practice, principles, and challenges. Sustainability Science 2012;7:25-43.

7 Turin TC, Chowdhury N, Haque S, et al. Meaningful and deep community engagement efforts for pragmatic research and beyond: engaging with an immigrant/racialised community on equitable access to care. BMJ Glob Health 2021;6:e006370.

8 Israel BA, Coombe CM, Cheezum RR, et al. Community-Based participatory research: a capacity-building approach for policy advocacy aimed at eliminating health disparities. Am J Public Health 2010;100:2094-102.

9 Wallerstein N, Duran B. Community-Based participatory research contributions to intervention research: the intersection of science and practice to improve health equity. Am J Public Health 2010;100 Suppl 1:S40-6.

10 Canadian Institutes of Health Research. Guide to knowledge translation planning at CIHR: integrated and end-of-grant approaches, 2015. Available: http://www.cihr-irsc.gc.ca/e/45321. html [Accessed on 15th July 2020].

11 Chen E, Leos C, Kowitt SD, et al. Enhancing community-based participatory research through human-centered design strategies. Health Promot Pract 2020;21:37-48.

12 Vaughn LM, Jacquez F, Lindquist-Grantz R, et al. Immigrants as research partners: a review of immigrants in communitybased participatory research (CBPR). J Immigr Minor Health 2017;19:1457-68.

13 Jull J, Giles A, Graham ID. Community-Based participatory research and integrated knowledge translation: advancing the co-creation of knowledge. Implementation Sci 2017;12:1-9.

14 Hacker K, Tendulkar SA, Rideout C, et al. Community capacity building and sustainability: outcomes of community-based participatory research. Prog Community Health Partnersh 2012;6:349-60.

15 Castelfranchi C. Six critical remarks on science and the construction of the knowledge Society. Journal of Science Communication 2007;06:C03.

16 Turin TC, Rashid R, Ferdous M, et al. Perceived challenges and unmet primary care access needs among Bangladeshi immigrant women in Canada. J Prim Care Community Health 2020;11:215013272095261.

17 Turin TC, Rashid R, Ferdous M, et al. Perceived barriers and primary care access experiences among immigrant Bangladeshi men in Canada. Fam Med Community Health 2020;8:e000453.

18 Turin TC, Haque S, Chowdhury N, et al. Overcoming the challenges faced by immigrant populations while accessing primary care: potential solution-oriented actions advocated by the Bangladeshi-Canadian community. J Prim Care Community Health 2021;12:215013272110101.

19 Turin TC, Haque S, Chowdhury N, et al. Community-Driven prioritization of primary health care access issues by BangladeshiCanadians to guide program of research and practice. Fam Community Health 2021:44:292-8.

20 Rodriguez R. Action research with immigrants working with vulnerable immigrant communities. in: Routledge international Handbook of migration studies. Routledge 2013pp.:564-75.

21 Katapally TR. The smart framework: integration of citizen science, community-based participatory research, and systems science for population health science in the digital age. JMIR Mhealth Uhealth 2019;7:e14056.

22 D'Alonzo KT. Getting started in CBPR: lessons in building community partnerships for new researchers. Nurs Inq 2010;17:282-8.

23 Wallerstein N, Oetzel J, Duran B, et al. What predicts outcomes in CBPR. Community-based participatory research for health: From process to outcomes 2008;2:371-92.

24 Israel BA, Krieger J, Vlahov D, et al. Challenges and facilitating factors in sustaining community-based participatory research partnerships: lessons learned from the Detroit, New York City and Seattle urban research centers. J Urban Health 2006;83:1022-40.

$25 \mathrm{Kim}$ HW. Research with children: challenges and dilemmas as an insider researcher. Early Child Dev Care 2012;182:263-76. 
researchers' identities on the community-based research process. $J$ 